\title{
Article \\ Big Data Analysis of the Key Attributes Related to Stress and Mental Health in Korean Taekwondo Student Athletes
}

\author{
Sung-Un Park ${ }^{1,+} \mathbb{D}^{\mathbb{D}}$, Jung-Woo Jeon ${ }^{2,+}$, Hyunkyun Ahn ${ }^{3}$, Yoon-Kwon Yang ${ }^{4, *,+}$ and Wi-Young So ${ }^{5, *,+}$ (D) \\ 1 Department of Sport \& Leisure Studies, College of Arts \& Physical Education, Shingyeong University, \\ Hwaseong-si 18274, Korea; psu@sgu.ac.kr \\ 2 Department of Taekwondo, College of Physical Education, Kyung Hee University, Yongin-si 17104, Korea; \\ jjw6267@khu.ac.kr \\ 3 Department of Sport \& Leisure Studies, Division of Arts \& Health, Myongji College, Seoul 03656, Korea; \\ ahnhk@mjc.ac.kr \\ 4 Department of Sport \& Leisure Studies, College of Health and Wellness, Sungshin Women's University, \\ Seoul 02844, Korea \\ 5 College of Humanities and Arts, Korea National University of Transportation, Chungju-si 27469, Korea \\ * Correspondence: yangyk@sungshin.ac.kr (Y.-K.Y.); wowso@ut.ac.kr (W.-Y.S.); Tel.: +82-2-920-7693 (Y.-K.Y.); \\ +82-43-841-5993 (W.-Y.S.) \\ + These authors contributed equally to this work.
}

Citation: Park, S.-U.; Jeon, J.-W.; Ahn, H.; Yang, Y.-K.; So, W.-Y. Big Data Analysis of the Key Attributes Related to Stress and Mental Health in Korean Taekwondo Student Athletes. Sustainability 2022, 14, 477. https://doi.org/10.3390/su14010477 Academic Editors: Sidonio Serpa and Jürgen Beckmann

Received: 3 December 2021

Accepted: 31 December 2021

Published: 3 January 2022

Publisher's Note: MDPI stays neutral with regard to jurisdictional claims in published maps and institutional affiliations.

Copyright: (c) 2022 by the authors. Licensee MDPI, Basel, Switzerland. This article is an open access article distributed under the terms and conditions of the Creative Commons Attribution (CC BY) license (https:// creativecommons.org/licenses/by/ $4.0 /)$.

\begin{abstract}
In the present study, we used big data analysis to examine the key attributes related to stress and mental health among Korean Taekwondo student-athletes. Keywords included "Taekwondo + Student athlete + Stress + Mental health". Naver and Google databases were searched to identify research published between 1 January 2010 and 31 December 2019. Text-mining analysis was performed on unstructured texts using TEXTOM 4.5, with social network analysis performed using UCINET 6. In total, 3149 large databases (1.346 MB) were analyzed. Two types of text-mining analyses were performed, namely, frequency analysis and term frequency-inverse document frequency analysis. For the social network analysis, the degree centrality and convergence of iterated correlation analysis were used to deduce the node-linking degree in the network and to identify clusters. The top 10 most frequently used terms were "stress", "Taekwondo", "health", "player", "student", "mental", "exercise", "mental health", "relieve", and "child." The top 10 most frequently occurring results of the TF-IDF analysis were "Taekwondo", "health", "player", "exercise", "student", "mental", "stress", "mental health", "child" and "relieve". The degree centrality analysis yielded similar results regarding the top 10 terms. The convergence of iterated correlation analysis identified six clusters: student, start of dream, diet, physical and mental, sports activity, and adult Taekwondo center. Our results emphasize the importance of designing interventions that attenuate stress and improve mental health among Korean Taekwondo student-athletes.
\end{abstract}

Keywords: Taekwondo; Korean student-athlete; stress; mental health

\section{Introduction}

Since Taekwondo was adopted as an official event in the Sydney Olympic Games in the year 2000, it has become internationally recognized as both a martial art and a sport [1]. As it has evolved into a modern Olympic sport [2], Taekwondo has grown significantly in popularity [3], with competitions now taking place in 210 countries across five continents [4]. In Korea, where the sport originated, there are currently 10,774 Taekwondo athletes, approximately $9800(90.96 \%)$ of whom are classified as student-athletes $(<13$ years, 1587; 13-15 years, 2690; 16-18 years, 3021; 19-22 years, 2502) [5].

Emphasis on success is prevalent in Taekwondo, as in other sports, including within Korea's elite sport system [6]. As an example, official Taekwondo competitions (qualifiers, semi-finals, and finals) are held on the same day [7]. This requires athletes to maintain peak physical condition over a prolonged period of time, while dealing with the pressure 
of competition and having to control their stress and anxiety prior to competing [8]. There is further pressure on student-athletes in Taekwondo as competitive results and academic achievement are the only factors determining progression to higher levels of education and career paths. Therefore, these athletes are generally compelled and even forced into prolonged cycles of competition that can significantly increase their experience of stress and pressure [9]. Yet, while the physical impact of participating in elite sports is well documented, there is a relative lack of research on the mental health of elite athletes [10].

Several studies have investigated whether martial arts such as Taekwondo improve mental health [11]. According to Moore et al. [12], who researched the positive effects of martial arts training on mental health: (a) male karate students reported less depression than other male college students [13], (b) a meta-analysis examining tai chi and mental health reported that 16 studies observed significant improvements in depression arising from tai-chi training, (c) subjects with behavioral problems who participated in a Taekwondo program for 6 months reported a significant decrease in anxiety [14], and (d) after studying Taekwondo for eight weeks, a group of female participants reported more characteristics associated with well-being (i.e., self-concept) than a comparison group [15] Similarly, elementary-school students who trained in Taekwondo had improved prosocial behavior compared to other martial arts groups [16,17].

However, some researchers have reported negative effects on adolescents who train in martial arts [18]. Participation in power sports, such as weightlifting, wrestling, and oriental martial arts (Taekwondo, judo, karate), increases antisocial behavior in adolescents [19]. This evidence indicates that there is uncertainty about the social-psychological outcomes of martial arts practice on young participants [18]. In addition, Taekwondo attack strategies mainly focus on powerful kicking techniques [20,21]. This attacking approach is quite different from other Olympic combat sports, such as boxing, wrestling, and judo [22]. Therefore, intense physical and technical training is important for elite Taekwondo athletes to improve their physical abilities [22]. Furthermore, along with the physical and technical difficulties of Taekwondo, Korean Taekwondo student-athletes experience different environmental characteristics compared to athletes in other sports and countries.

In Korea, many young children practice Taekwondo [23]. However, only 5711 middleand high-school student-athletes are registered with the Korean Olympic Committee [5], and even among them, $44 \%$ quit sports as athletes after beginning college [5]. Why do many Taekwondo student-athletes not continue to exercise? In 1972, the government of the Republic of Korea introduced the "College Sports Specialist Entrance Examination System" so that student-athletes could focus on training without being burdened by their studies [24]. Through this system, student-athletes were able to gain admissions to universities based on competition scores and not academic achievements. As a result of this system, training time increased, such as training 6 days a week and training 4 times a day, and camp training became a common practice in schools to aid student-athlete life management [25,26]. In Korea, about 30 universities have established and operated Taekwondo departments [27]. Admission to a prestigious university in Korea is especially important because it greatly affects the careers and employment of students [28]. Many of the Taekwondo student-athletes are de-socialized from Taekwondo due to the physical strain and the achievement of the goal of entering college [29]. In other words, while training, Taekwondo student-athletes are exposed to additional stress [30] from an education system centered on grades and college entrance exams, compared to other students [29]. Therefore, although these psychological stresses are expected to affect mental health, unfortunately, epidemiological studies on the mental health of Korean Taekwondo student-athletes have not been attempted. In addition, current research available on Taekwondo has focused primarily on adult male athletes [7] and competitions [31-33].

Accordingly, our goal in this study was to analyze the key attributes related to the stress and mental health of Korean Taekwondo student-athletes through an analysis of the unstructured data on this topic identified in Naver (NAVER Corp., Seongnam, Korea) and Google (Alphabet Inc., Mountain View, CA, USA). Identifying factors that influence 
the stress and mental health of student-athletes through big data analysis will provide basic academic data regarding their psychological state, allowing for the development of strategic interventions to improve the mental and physical health of these student-athletes.

\section{Literature Review}

\subsection{Sports, Taekwondo, and Sustainability}

The 17 SDGs (Sustainable Development Goals) of the 70th UN General Assembly in 2015 are an agenda, to be achieved by 2030, for humankind to realize the philosophy of sustainable development [34]. The president of the International Olympic Committee (IOC), Thomas Bach, emphasized that sports will be more effective than any other means for achieving goals $3,4,5,16$, and 17 of these 17 development goals [35].

Sports and development can be largely interpreted as two perspectives: "development of sports" and "development through sports" [36]. Although these two approaches have something in common, in that they encourage participation in sports, there is a clear difference in their goals $[37,38]$. From the 1970s to the present day, Korea has been contributing to official development assistance, a part of international development cooperation, through the overseas dispatch of Taekwondo masters [39].

\subsection{Stress and Mental Health}

Stress is the body's response to a challenge or demand, manifesting as emotional or physical tension. Stress can be caused by any event or thought that makes one feel angry, nervous, or frustrated [40]. According to the World Health Organization [41], "Mental health is a state of well-being in which an individual realizes his or her own abilities, can cope with the normal stresses of life, can work productively, and is able to make a contribution to his or her community." This definition is important in that it emphasizes that mental health is more than just the absence of a mental disorder or disability [41].

Stress is common at every stage of life. Previous research has indicated that, as of 2019, 51.5 million adults in the United States experience mental health problems each year [42]. Although this prevalence suggests that approximately 1 in 5 American adults experience mental health issues, social issues influencing mental health are more likely to affect young individuals during key periods of socialization. In Korea, 1 in 4 adults has suffered from a mental illness such as stress, depression, or anxiety at least once [43]. In a situation where the level of mental health of Korean adults is more serious than that of the United States, the number of adolescents receiving treatment for mental illness is steadily increasing, from 22,587 in 2016 to 275,557 in 2020 [44]. These factors are important to consider as the physical and mental changes occurring during adolescence are critical determinants of health in adulthood [45]. Adolescents may not have the strategies to cope with social pressure and stress, which places them at high risk of mental illness [46,47]. Moreover, students often experience psychological pressure [48-51]. This psychological pressure can be increased in student-athletes in Korea, who commonly choose to pursue their sporting careers at the expense of their education, which increases the pressure on sports performance and outcomes. In fact, under the elite sporting system, school absences are common from as early as middle school [6]. Therefore, Korean student-athletes experience significant stress in all areas of their lives, both as students and athletes [24].

\subsection{Big Data}

The term "big data" denotes a large volume of complex and rapidly growing datasets from numerous autonomous and independent sources [52]. Big data is distinct from standard data in terms of volume, velocity, and variety [53], reflecting the faster rate at which modern data is generated than in the past. Accordingly, big data achieves near realtime velocity and greater variety than traditional data. In turn, techniques for analyzing big data have become increasingly diversified in recent years [54-56]. Currently, Korea offers favorable conditions for big data to flourish, by virtue of its globally superior network infrastructures and the immense amount of data produced [57-59]. Therefore, big data 
analysis has the potential to expand research in various fields, such as discourse analyses on social phenomena, cognitive analyses, securing product competitiveness via analyses of changes in social trends, and the creation of value through the examination of new convergences.

\subsubsection{Text-Mining Analysis}

Text-mining analysis is the process of discovering new knowledge from the large-scale volume and variety of a selected digital text set [60-63]. This involves extracting relevant terms, calculating their frequency of use, and determining their meaning [64]. In this study, text-mining analysis was performed using both frequency and term frequency-inverse document frequency (TF-IDF) analyses. Frequency analysis calculates the number of times a term appears in a given document, using the TF-IDF approach to weigh each term according to its uniqueness in a text document $[59,65]$. Thus, the TF-IDF value increases as the frequency of instances of a particular word in a specific document increases, while the number of documents including the specific word decreases [59].

\subsubsection{Social Network Analysis}

Social network analysis (SNA) is a strategy for investigating social structures [66]. Furthermore, SNA can be used to quantitatively analyze the characteristics of objects that constitute a social network model, using nodes and links [67]. In this study, SNA was performed using both degree centrality and the convergence of iterated correlation (CONCOR) analysis. Degree centrality refers to the sum of the nodes connected to a central node in a given network. This makes it possible to determine the number of nodes with which a central node exhibits a relationship. CONCOR analysis was performed to analyze the structures of the relationships among the latent sub-clusters (i.e., the relationships and patterns between words). The greater the similarity between the relationships and patterns, the greater the degree of structural equivalence between the other words [68].

\section{Materials and Methods}

\subsection{Research Procedure}

The research procedure, which involved big data analysis, is shown in Figure 1. First, data were collected and refined using the big data collection and analysis solution presented by TEXTOM 4.5 (The Imc Inc., Daegu, Korea). This software automatically collects text data, refines it through a stemmer, and counts the frequency of words to create a matrix of selected words [69]. TEXTOM is an analysis package made for easy access by users, implementing the full text software developed by Professor Loet Leydesdorff (University of Amsterdam) on the web, for Korean analysis by TEXTOM 4.5 (The Imc Inc., Daegu, Korea) in Korea [70]. The resulting software, released by the Korea Information and Communication Technology Association [71], is currently being used successfully in various studies registered with the National Research Foundation of Korea [72]. Second, the top 50 words were derived through text-mining analysis (including both frequency and TF-IDF analysis) of the refined data. Third, the selected data were converted into matrix format to perform the SNA (including both degree centrality and CONCOR analysis) using UCINET 6 (Analytic Technologies Corp., Lexington, KY, USA). Finally, the derived data were visualized using tables and figures. The steps of this process are shown in Figure 1. 


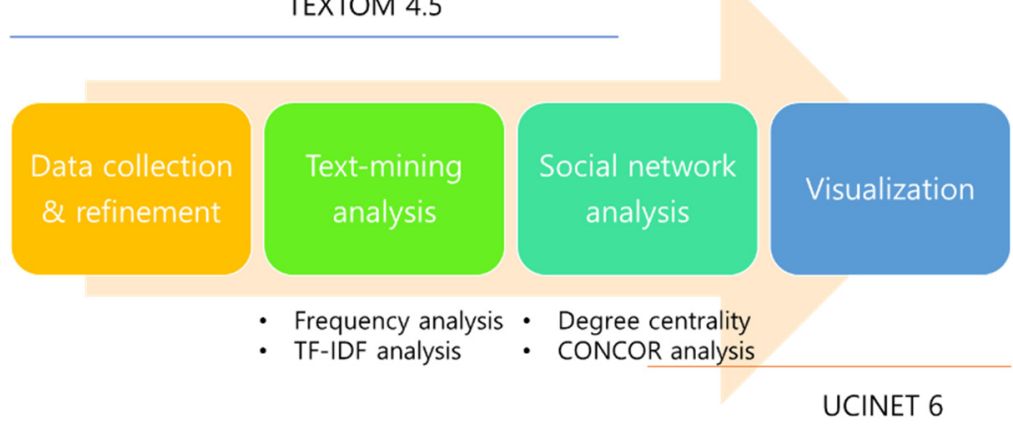

Figure 1. Research procedure.

\subsection{Data Collection and Refinement}

This study was approved by the Institutional Review Board of Kyung Hee University, Global Campus, Gyeonggi, Korea (No. KHGIRB-20-672). The data collection period extended from 1 January 2010, to 31 December 2019. Search terms were as follows: "Taekwondo + Student athlete + Stress + Mental health" (the meaning of + is that the data must include these words). The big data collection and analysis solution of the web crawling program TEXTOM 4.5 (http: / / textom.co.kr; accessed on 2 December 2021) was used to collect unstructured text from webpages, blogs, and news articles [73], as provided by Naver and Google, which are the most commonly used search engines in Korea [74].

In this study, data collection referred to the identification and clarification of the types of information being investigated. The scope of the collected data was limited to the characteristics of the keywords. The process of converting unstructured text data into a structured format is known as data refinement [68]. During data refinement, the monosyllabic parts of Korean speech were deleted as they did not represent the correct meaning.

\subsection{Data Analysis}

In this study, both text mining and SNA were performed to determine the level of stress and mental health effects in Taekwondo student-athletes in Korea. TEXTOM 4.5's big data analysis solution, as well as the Netdraw visualization tool of the UCINET 6 social network analysis software [54], were used to perform both text-mining and SNA.

\section{Results}

\subsection{Results of Data Collection}

In this study, we collected texts related to the keywords "Taekwondo + Student athlete + Stress + Mental health" that were published in Korea on Naver and Google between 1 January 2010 and 31 December 2019. The results are shown in Table 1. In total, 3149 data points were collected using TEXTOM 4.5, with the total volume of data amounting to $1.346 \mathrm{MB}$.

Table 1. Collection channels, number of data points, and volume.

\begin{tabular}{ccc}
\hline Collection Channel & Number of Data Points & Volume \\
\hline Naver & 2130 & $1.051 \mathrm{MB}$ \\
Google & 1019 & $0.295 \mathrm{MB}$ \\
Total & 3149 & $1.346 \mathrm{MB}$ \\
\hline
\end{tabular}

\subsection{Text-Mining Analysis}

The results of the frequency analysis of the top 50 terms related to the stress and mental health of Taekwondo student-athletes are shown in Table 2. Our findings indicated that the top 10 most frequently used terms were "stress" (886), "Taekwondo" (693), "health" 
(469), "player" (390), "student" (387), "mental" (311), "exercise" (304), "mental health" (199), "relieve" (173), and "child" (157).

Table 2. Results of the frequency analysis.

\begin{tabular}{|c|c|c|c|c|c|}
\hline Rank & Term & Frequency & Rank & Term & Frequency \\
\hline 1 & Stress & 886 & 26 & Adolescent & 55 \\
\hline 2 & Taekwondo & 693 & 27 & Influence & 51 \\
\hline 3 & Health & 469 & 28 & High school student & 50 \\
\hline 4 & Player & 390 & 29 & Training & 48 \\
\hline 5 & Student & 387 & 30 & Friend & 48 \\
\hline 6 & Mental & 311 & 31 & Mind & 47 \\
\hline 7 & Exercise & 304 & 32 & Need & 46 \\
\hline 8 & Mental health & 199 & 33 & Activity & 46 \\
\hline 9 & Relieve & 173 & 34 & Effect & 45 \\
\hline 10 & Child & 157 & 35 & Time & 45 \\
\hline 11 & Person & 103 & 36 & Start & 44 \\
\hline 12 & Elementary school student & 95 & 37 & Adult & 44 \\
\hline 13 & Sports & 86 & 38 & Competition & 44 \\
\hline 14 & Work & 75 & 39 & MOOTO & 43 \\
\hline 15 & Physical & 73 & 40 & Education & 41 \\
\hline 16 & Diet & 71 & 41 & Life & 41 \\
\hline 17 & Study & 71 & 42 & Physical strength & 41 \\
\hline 18 & Body & 68 & 43 & Korea & 40 \\
\hline 19 & Boxing & 65 & 44 & Improving & 40 \\
\hline 20 & School & 62 & 45 & Happiness & 40 \\
\hline 21 & Help & 61 & 46 & Flesh & 39 \\
\hline 22 & Athlete & 60 & 47 & Management & 39 \\
\hline 23 & Taekwondo center & 59 & 48 & Kickboxing & 39 \\
\hline 24 & Talk & 58 & 49 & Myself & 38 \\
\hline 25 & Think & 57 & 50 & Dream & 37 \\
\hline
\end{tabular}

Note: $\mathrm{MOOTO}=\mathrm{A}$ Taekwondo Corporation in Korea.

Second, as shown in Table 3, the top 10 most frequently occurring results of the TF-IDF analysis were "Taekwondo" (697.357), "health" (587.001), "player" (525.824), "exercise" (521.561), "student" (505.935), "mental" (478.436), "stress" (428.873), "mental health" (379.076), "child" 370.265), and "relieve" (352.649). Unlike the results of the frequency analysis, the ranking of "exercise" slightly increased in the TF-IDF analysis, while the ranking of "stress" decreased.

\subsection{Social Network Analysis (SNA)}

In this study, degree centrality and CONCOR analyses were used to perform SNA. A higher degree of centrality was considered to indicate a significant number of links among the terms, resulting in a significant impact on the overall network [54]. Therefore, degree centrality analysis was performed to examine how connected the derived terms were to "Taekwondo + Student athlete + Stress + Mental health" (Table 4). The top 10 most frequently occurring results of the degree centrality analysis were "stress" (0.095628), “Taekwondo" (0.077691), "student" (0.054709), "player" (0.051682), "health" (0.041592), "exercise" (0.037108), "mental" (0.031726), "mental health" (0.027018), "child" (0.021973), and "person" (0.016143). Unlike the results of the text-mining analysis, the ranking of "person" increased slightly in the degree centrality analysis, while the ranking of "relieve" decreased. 
Table 3. TF-IDF results.

\begin{tabular}{|c|c|c|c|c|c|}
\hline Rank & Term & TF-IDF & Rank & Term & TF-IDF \\
\hline 1 & Taekwondo & 679.357 & 26 & Think & 180.885 \\
\hline 2 & Health & 587.001 & 27 & MOOTO & 179.167 \\
\hline 3 & Player & 525.824 & 28 & Training & 169.191 \\
\hline 4 & Exercise & 521.561 & 29 & Influence & 168.925 \\
\hline 5 & Student & 505.935 & 30 & $\begin{array}{l}\text { High school } \\
\text { student }\end{array}$ & 168.910 \\
\hline 6 & Mental & 478.436 & 31 & Friend & 162.154 \\
\hline 7 & Stress & 428.873 & 32 & Competition & 159.986 \\
\hline 8 & Mental health & 379.076 & 33 & Mind & 158.776 \\
\hline 9 & Child & 370.265 & 34 & Adult & 157.471 \\
\hline 10 & Relieve & 352.649 & 35 & Need & 156.455 \\
\hline 11 & Person & 274.247 & 36 & Activity & 156.455 \\
\hline 12 & Elementary school student & 256.167 & 37 & Effect & 156.308 \\
\hline 13 & Sports & 250.596 & 38 & Time & 153.054 \\
\hline 14 & Work & 220.717 & 39 & Start & 152.835 \\
\hline 15 & Diet & 220.239 & 40 & Education & 149.078 \\
\hline 16 & Study & 220.239 & 41 & $\begin{array}{l}\text { Physical } \\
\text { strength }\end{array}$ & 146.734 \\
\hline 17 & Physical & 219.257 & 42 & Improving & 145.442 \\
\hline 18 & Boxing & 206.272 & 43 & Kickboxing & 145.408 \\
\hline 19 & Body & 205.310 & 44 & Life & 144.517 \\
\hline 20 & School & 196.752 & 45 & Korea & 143.155 \\
\hline 21 & Taekwondo center & 194.181 & 46 & Dream & 143.063 \\
\hline 22 & Athlete & 192.669 & 47 & Management & 141.805 \\
\hline 23 & Help & 188.177 & 48 & Happiness & 140.993 \\
\hline 24 & Adolescent & 185.801 & 49 & Program & 136.624 \\
\hline 25 & Talk & 181.949 & 50 & Flesh & 136.455 \\
\hline
\end{tabular}

Note: TF-IDF = Term frequency-inverse document frequency analysis.

Second, a CONCOR analysis was performed to analyze the structures of the relationships among the latent sub-clusters in the network. The results are presented in Table 5 and Figure 2. Based on these results, homogenous groups were identified according to their shared relationships and correlations, resulting in six clusters (including students, the start of dreams, diet, physical and mental state, sports activity, and adult Taekwondo center). The first cluster (visualized in yellow) included the terms "school", "student", "study", "mental health", "work", "time", "need", "friends", "improving", and "Taekwondo", and was categorized as "student." The second cluster (visualized in green) included the terms "start", "dream", "think", "talk", "Korea", "player", and "elementary school student", and was categorized as "start of dream." The third cluster (visualized in white) included the terms "diet", "relieve", "effect", "boxing", and "kickboxing", and was categorized as "diet". The fourth cluster (visualized in orange) included the terms "physical", "mental", "health", "person", "life", "help", "mind", "body", "flesh", and "management", and was categorized as "physical and mental." The fifth cluster (visualized in red) included the terms "sports", " activity", "stress", "child", "adolescent", "athlete", "myself", "physical strength", "influence", and "education", and was categorized as "sports activity". The sixth cluster (visualized in purple) included the terms "adult", "Taekwondo center", "training", and "MOOTO", and was categorized as "adult Taekwondo center". The terms "high school student", "competition", and "happiness" did not form clusters. 
Table 4. Results of the degree centrality analysis.

\begin{tabular}{|c|c|c|c|c|c|}
\hline Rank & Term & $\begin{array}{c}\text { Degree } \\
\text { Centrality }\end{array}$ & Rank & Term & $\begin{array}{l}\text { Degree } \\
\text { Centrality }\end{array}$ \\
\hline 1 & Stress & 0.095628 & 26 & Help & 0.007960 \\
\hline 2 & Taekwondo & 0.077691 & 27 & Adolescent & 0.007848 \\
\hline 3 & Student & 0.054709 & 28 & Time & 0.007735 \\
\hline 4 & Player & 0.051682 & 29 & Adult & 0.007623 \\
\hline 5 & Health & 0.041592 & 30 & Activity & 0.007511 \\
\hline 6 & Exercise & 0.037108 & 31 & High school student & 0.007287 \\
\hline 7 & Mental & 0.031726 & 32 & Education & 0.007063 \\
\hline 8 & Mental health & 0.027018 & 33 & Life & 0.007063 \\
\hline 9 & Child & 0.021973 & 34 & Effect & 0.007063 \\
\hline 10 & Person & 0.016143 & 35 & Korea & 0.006951 \\
\hline 11 & $\begin{array}{c}\text { Elementary school } \\
\text { student }\end{array}$ & 0.015471 & 36 & Mind & 0.006951 \\
\hline 12 & Sports & 0.013453 & 37 & Training & 0.006726 \\
\hline 13 & Work & 0.012556 & 38 & Physical strength & 0.006726 \\
\hline 14 & Relieve & 0.010987 & 39 & Myself & 0.006390 \\
\hline 15 & School & 0.010762 & 40 & Influence & 0.006390 \\
\hline 16 & Athlete & 0.010538 & 41 & Dream & 0.006166 \\
\hline 17 & Talk & 0.010202 & 42 & Happiness & 0.006166 \\
\hline 18 & Boxing & 0.010090 & 43 & Competition & 0.006054 \\
\hline 19 & Think & 0.009978 & 44 & Case & 0.005942 \\
\hline 20 & Study & 0.009641 & 45 & Taekwondo center & 0.005942 \\
\hline 21 & Diet & 0.009529 & 46 & Research & 0.005717 \\
\hline 22 & Body & 0.008969 & 47 & Physical & 0.005717 \\
\hline 23 & Need & 0.008632 & 48 & Degree & 0.005605 \\
\hline 24 & Friend & 0.008072 & 49 & Relive stress & 0.005605 \\
\hline 25 & Start & 0.007960 & 50 & Parents & 0.005605 \\
\hline
\end{tabular}

Table 5. Results of the CONCOR analysis.

\begin{tabular}{|c|c|c|}
\hline & Cluster & Terms \\
\hline 1 & Student & $\begin{array}{c}\text { Student, School, Study, Mental health, Work, Time, Need, } \\
\text { Friend, Improving, Taekwondo }\end{array}$ \\
\hline 2 & Start of dream & $\begin{array}{c}\text { Start, Dream, Think, Talk, Korea, Player, Elementary } \\
\text { school student }\end{array}$ \\
\hline 3 & Diet & Diet, Relieve, Effect, Boxing, Kickboxing \\
\hline 4 & Physical and mental & $\begin{array}{l}\text { Physical, Mental, Health, Person, Life, Help, Mind, Body, } \\
\text { Flesh, Management }\end{array}$ \\
\hline 5 & Sports activity & $\begin{array}{l}\text { Sports, Activity, Stress, Child, Adolescent, Athlete, Myself, } \\
\text { Physical strength, Influence, Education }\end{array}$ \\
\hline 6 & Adult Taekwondo center & Adult, Taekwondo center, Training, MOOTO \\
\hline
\end{tabular}

Note: CONCOR = convergence of iterated correlations, MOOTO = Taekwondo Corporation in Korea. 


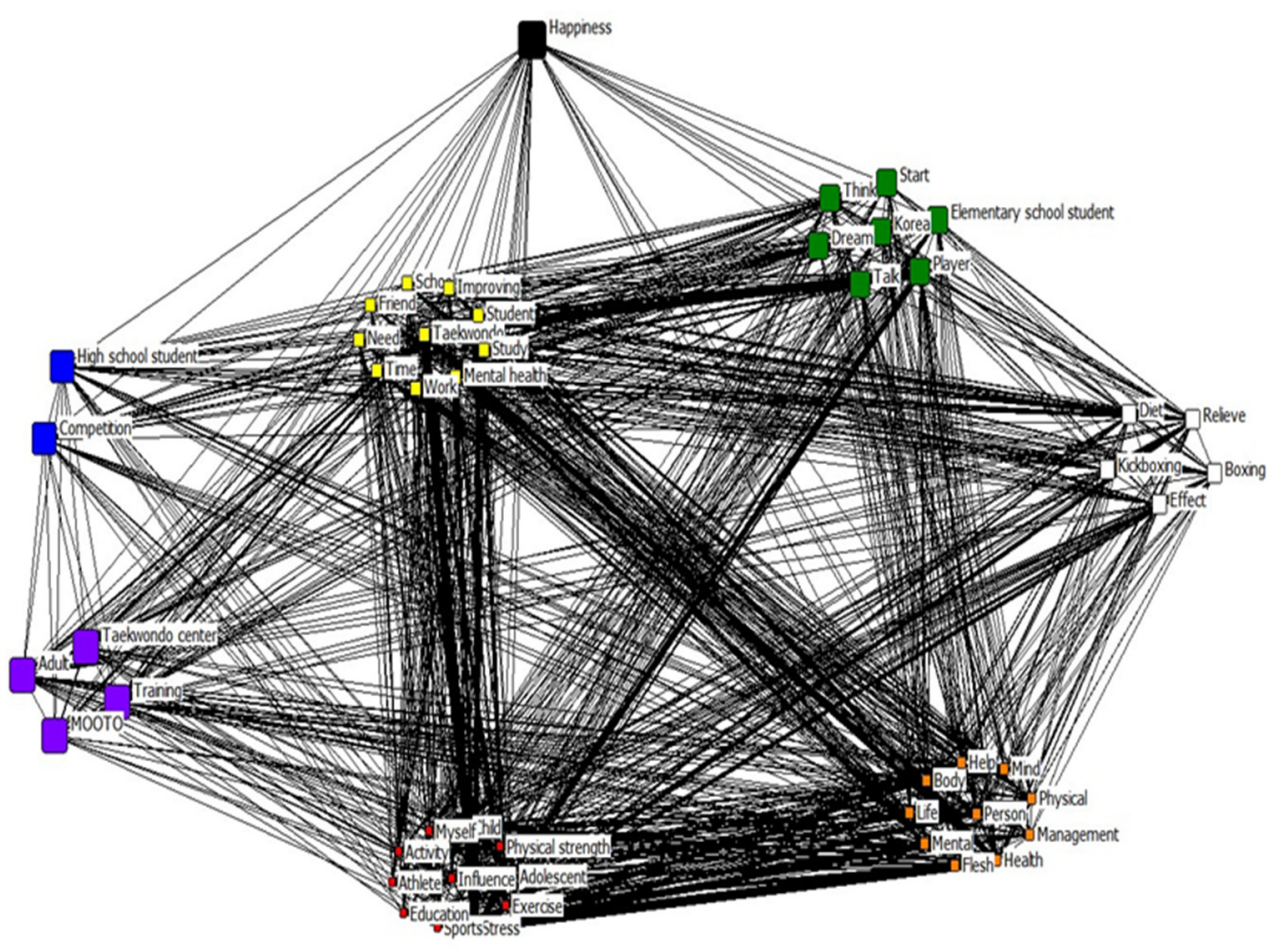

Figure 2. CONCOR analysis results. Note: Yellow cluster $=$ student, green cluster $=$ start of dream, white cluster $=$ diet, orange cluster $=$ physical and mental, red cluster $=$ sports activity, purple cluster $=$ adult Taekwondo center, blue and black $=$ did not form a cluster. CONCOR $=$ Convergence of iterated correlations.

\section{Discussion}

In this study, we investigated key terms related to the stress and mental health of Korean Taekwondo student-athletes using big data analysis. The terms "stress", "Taekwondo", "health", "players", "students", "mental", "exercise", and "mental health" were highly ranked in our frequency, TF-IDF, and degree of centrality analyses of data published over the last 10 years.

Taekwondo competitions are held according to weight category, meaning that athletes must maintain a constant body weight until the start of the match [75-77]. This process can cause physical, physiological, and psychological stress by forcing players to rely on strategies such as rapid dehydration [77-79]. In addition, combat sports, such as Taekwondo, are considered among the most traumatic types of sports due to the quality and frequency of the inherent contact involved [80,81]. Furthermore, according to Jeon and Park [29], Korean Taekwondo athletes are unable to consistently participate in their studies as they commonly focus primarily on their sports training. Therefore, it is necessary to introduce a system that monitors the stress and mental health of Taekwondo studentathletes, with the aim of preventing the development of future problems. To classify the similarity within the constructed network, the results of the CONCOR analysis were classified into six clusters: student, start of dream, diet, physical and mental, sports activity, and adult Taekwondo center. Of note, the terms "high school student", "competition", and "happiness" did not form clusters.

First, Taekwondo student-athletes experience high levels of stress in their role as students (student cluster). The Korean Ministry of Culture, Sports, and Tourism launched the Sports Innovation Committee in February 2019 to improve the structure of Korea's elite sports system [82]. The Sports Innovation Committee emphasized the need for a comprehensive reform of the school sport development system, in which it was common for student-athletes to neglect their education to focus on their sport [82]. Despite these recommendations, there have been no attempts to resolve the issues surrounding academic stress among student-athletes. Reforming Korea's elite sporting system will help 
improve the environment in which Taekwondo student-athletes function, which will, in turn, provide physical and psychological benefits.

Second, the dream cluster highlights the unique Korean socio-cultural context in which student-athletes choose to begin their careers as early as possible in order to reach an elite level. Indeed, even at the elementary school level, Korean Taekwondo student-athletes tend to begin their athletic careers with the goal of becoming elite Taekwondo athletes. However, exercise cessation due to excessive training, injury, motivation, and/or stress has been reported in young athletes $[83,84]$. Therefore, there is a need to formulate a long-term plan that is conducive to the holistic development of young student-athletes, rather than focusing only on their physical and motor development for specific sport participation [85]. We hope that this strategy will help more student-athletes to achieve their dreams.

Third, as highlighted by the diet cluster, Taekwondo is a sport that requires strong dietary restriction and weight loss, such as that achieved through boxing and kickboxing. In particular, according to Barley et al. [86], martial arts athletes engage in more weight loss strategies than athletes participating in other combat sports. However, because most student-athletes are under the age of 19 years [5], maintaining an appropriate weight and participating in weight class competitions, rather than engaging in indiscriminate weight-loss strategies, will improve their overall level of stress and mental health.

Fourth, as revealed by the physical and mental cluster, most student-athletes who participate in sports, such as Taekwondo, engage in constant exercise to achieve an optimal fitness level. The exercise that they undergo differs from that of other student-athletes who do not experience weigh-ins. However, losing weight in order to achieve an optimal fitness level $[87,88]$ can negatively affect physical and mental health [89], increase their levels of stress hormones [90], decrease athletic performance [91-95], and lead to exhaustion, which is often regarded as unconscious avoidance in response to diverse stressors [96,97]. Therefore, systematic coaching programs that contribute to increases in student-athletes' positive emotional experiences are required, given that these emotional experiences are conducive to the formation of a strong sense of identity and self-esteem, which can help to alleviate exhaustion [98]. Such programs may substantially contribute to reducing stress and improving the mental health of Korean Taekwondo student-athletes.

Fifth, as indicated by the sports activity cluster, student-athletes are expected to meet their fundamental goals and foster necessary competencies with diverse experiences [99]. Thus, we need to help Taekwondo student-athletes experience a diverse range of sporting activities to ease their stress levels, develop positive social networks, and foster ethical behaviors-a process known as holistic development [100]. However, performance-first policies in elite sports programs ignore the quality of life and future functioning of studentathletes. Therefore, education programs must acknowledge that athletes are students first, meaning that more holistic rather than performance-first strategies for career development are required to ensure optimal academic input in combination with athletic outcomes. Such programs will allow students to maintain their best performance, engage in creative play, undergo persistent practice, and experience well-coordinated team playing from the early stages to when they enter higher elite levels.

Sixth, in reference to the adult Taekwondo center cluster, $90 \%$ of Taekwondo centers in Korea are composed of elementary-school students [101]. However, Taekwondo centers are the primary places in which people can practice this sport; adults are often unable to practice the sport in centers dedicated to children and adolescents, given the high-stress environment designed to produce elite athletes. For this reason, adult Taekwondo centers (e.g., MOOTO) have emerged to meet the needs of training adults. Therefore, the stress and mental health of Taekwondo student-athletes are closely related to adult Taekwondo training.

Finally, our analysis revealed that "high school student", "competition", and "happiness" did not form a cluster. In Korea's elite sporting system, it is critical for high-school student-athletes to enter college by undertaking competitions. However, a previous study noted that more than $40 \%$ of freshmen and junior students who entered college as athletes 
stopped practicing their sports later on because they became emotionally and physically exhausted [102]. It should be made clear that college admission is not the only life goal to which one can aspire, and that the happiness of student-athletes is paramount for their holistic development. In support of this attitude, the National Collegiate Athletic Association publishes Mental Health Best Practices, which are developed and approved by proven institutions to support and promote the mental health of student-athletes [103]. Thus, considering the terms and clusters identified in this study, a system that can support and promote mental health, such as the mental health practice guidelines of Korean student-athletes, is required.

\section{Conclusions}

In this study, we conducted a big data analysis to investigate the key attributes related to stress and mental health in Korean Taekwondo student-athletes. The top 50 terms were derived through frequency, TF-IDF, and degree centrality analyses. Among these 50 items, "stress", “Taekwondo", "health", "players", "students", "mental", "exercise", and "mental health" were some of the most highly ranked terms. In addition, CONCOR analysis identified six clusters, which were labeled as follows: "student", "start of dream", "diet", "physical and mental", "sports activity", and "adult Taekwondo center". These results highlight the need to develop a strategic intervention for ameliorating stress and improving mental health among Korean Taekwondo student-athletes. Therefore, if a stress reduction and mental health promotion program is developed based on the six derived clusters, it can contribute to the development of guidelines regarding the mental health of Taekwondo student-athletes. These mental health guidelines can also serve as useful mental health standards for student-athletes and their coaches.

However, approaches like big data analysis have limitations in specifically identifying individual stress levels, such as performance, exercise, and career choices of Taekwondo student-athletes, as well as manifestations of mental disorders, such as the abuse of drugs, school violence, and bullying. Furthermore, although the results of this study may be useful for the Korean population, there are limitations in the characteristics of the sample, and therefore the results must be interpreted with caution for other cultures. Additional epidemiological studies are required to determine the factors influencing stress and mental health in this population and to identify strategies for improving the overall well-being and development of student-athletes. Therefore, in a follow-up study, an epidemiological investigation on the mental health of Taekwondo student-athletes is required. In addition, research on the development and application of mental health programs centering on the six derived clusters is also required.

Author Contributions: Study design: S.-U.P. and W.-Y.S. Study conduct: S.-U.P., J.-W.J., H.A. and Y.-K.Y. Data collection: S.-U.P. and W.-Y.S. Data analysis: S.-U.P. Data interpretation: S.-U.P. Drafting manuscript: S.-U.P., J.-W.J., H.A., Y.-K.Y. and W.-Y.S. Revising the manuscript content: S.-U.P., H.A. and W.-Y.S. All authors have read and agreed to the published version of the manuscript.

Funding: This research received no external funding.

Institutional Review Board Statement: This study was approved by the Institutional Review Board of Kyung Hee University, Global Campus, Gyeonggi, Korea (No. KHGIRB-20-672).

Informed Consent Statement: Not applicable.

Data Availability Statement: Not applicable.

Conflicts of Interest: The author declares no conflict of interest.

\section{References}

1. Kim, H.B.; Johnson, J.A.; Lee, E.J.; Ha, P. An investigation into the history of the Taekwondo uniform since the Korean peninsula's liberation from Japan. Int. J. Hist. Sport 2016, 33, 963-977. [CrossRef]

2. Bridge, C.A.; da Silva Santos, J.F.; Chaabene, H.; Pieter, W.; Franchini, E. Physical and physiological profiles of taekwondo athletes. Sports Med. 2014, 44, 713-733. [CrossRef] [PubMed] 
3. Kazemi, M.; Waalen, J.; Morgan, C.; White, A.R. A profile of Olympic taekwondo competitors. J. Sports Sci. Med. 2006, 5, 114. [PubMed]

4. World Taekwondo. Members: Seoul, Korea. 2020. Available online: http://www.worldtaekwondo.org/about-wt/members/ (accessed on 16 December 2020).

5. Korean Olympic Committee. Statistical Status of Professional Sports Registration, Seoul, Korea. 2020. Available online: https://g1.sports.or.kr/stat/stat01.do (accessed on 16 December 2020).

6. Park, J.W.; Lim, S.Y.; Bretherton, P. Exploring the truth: A critical approach to the success of Korean elite sport. J. Sport Soc. Issues 2012, 36, 245-267. [CrossRef]

7. Chiodo, S.; Tessitore, A.; Cortis, C.; Cibelli, G.; Lupo, C.; Ammendolia, A.; De Rosas, M.; Capranica, L. Stress-related hormonal and psychological changes to official youth Taekwondo competitions. Scand. J. Med. Sci. Sports 2011, 21, 111-119. [CrossRef] [PubMed]

8. Lim, T.; O'Sullivan, D.M. Case study of mental skills training for a taekwondo Olympian. J. Hum. Kinet. 2016, 50, 235-245. [CrossRef]

9. Park, S.; Kim, W. Taekwondo players' stand-alone course: Narrative approach to student players' continuous sports activities. Taekwondo J. Kukkiwon 2018, 9, 95-119.

10. Rice, S.M.; Purcell, R.; De Silva, S.; Mawren, D.; McGorry, P.D.; Parker, A.G. The mental health of elite athletes: A narrative systematic review. Sports Med. 2016, 46, 1333-1353. [CrossRef]

11. Macarie, I.; Roberts, R. Martial arts and mental health. Contemp. Psychother. 2010, 2, 1-4.

12. Moore, B.; Dudley, D.; Woodcock, S. The effect of martial arts training on mental health outcomes: A systematic review and meta-analysis. J. Bodyw. Mov. Ther. 2020, 24, 402-412. [CrossRef]

13. McGowan, R.; Jordan, C. Mood states and physical activity. La. Alliance Health Phys. Educ. Recreat. Danc. J. 1988, 15, 12-13.

14. Trulson, M.E. Martial arts training: A novel "cure" for juvenile delinquency. Hum. Relat. 1986, 39, 1131-1140. [CrossRef]

15. Finkenberg, M.E. Effect of participation in taekwondo on college women's self-concept. Percept. Mot. Ski. 1990, 71, 891-894. [CrossRef]

16. Lakes, K.D.; Hoyt, W.T. Promoting self-regulation through school-based martial arts training. J. Appl. Dev. Psychol. 2004, 25, 283-302. [CrossRef]

17. Strayhorn, J.M.; Strayhorn, J.C. Martial arts as a mental health intervention for children? Evidence from the ECLS-K. Child Adolesc. Psychiatry Ment. Health 2009, 3, 32. [CrossRef]

18. Vertonghen, J.; Theeboom, M. The social-psychological outcomes of martial arts practise among youth: A review. J. Sports Sci. Med. 2010, 9, 528. [PubMed]

19. Endresen, I.M.; Olweus, D. Participation in power sports and antisocial involvement in preadolescent and adolescent boys. $J$. Child Psychol. Psychiatry 2005, 46, 468-478. [CrossRef]

20. Pieter, W.; Heijmans, J. Scientific Coaching for Olympic Taekwondo; Meyer and Meyer Sport: Aachen, Germany, 1997.

21. Whang, S.C.; Whang, J.C.; Saltz, B. Taekwondo: The State of the Art; Broadway Books: New York, NY, USA, 1999.

22. Liao, Y.H.; Sung, Y.C.; Chou, C.C.; Chen, C.Y. Eight-week training cessation suppresses physiological stress but rapidly impairs health metabolic profiles and aerobic capacity in elite taekwondo athletes. PLoS ONE 2016, 11, e0160167. [CrossRef]

23. Jung, H.C.; Song, J.K. Decreased abdominal fat and improved bone metabolism after taekwondo training in obese adolescents. Kinesiology 2018, 50, 79-88. [CrossRef]

24. Korean Ministry of Gender Equality and Family. Great Debate for the Protection of Student Athletes' Rights. 2011. Available online: https:/ / www.kyci.or.kr/ fileup/lib_pdf/2011-66.pdf (accessed on 12 October 2021).

25. Kim, D.H. The process of adjustment to the school Lives from a normal student to a student athlete. Korean Assoc. Sport Pedagog. 2011, 18, 71-90.

26. Lee, Y.S. Analysis and improvement direction of refugee training extermination policy refusal. Natl. Athl. Compet. Commem. Conf. Rep. 2015, 54, 376

27. Park, S.U.; Kim, H.Y. The relationship between career intention and career behavior of college Taekwondo students applying theory of planned behavior. Taekwondo J. Kukkiwon 2019, 10, 129-146.

28. Lee, S.H.; Brinton, M.C. Elite education and social capital: The case of South Korea. Sociol. Educ. 1996, 69, 177-192. [CrossRef]

29. Jeon, J.W.; Park, S.U. A process for desocialization and re-socialization of taekwondo player's. Korean J. Phys. Educ. 2009, 48, 53-63.

30. Park, S.U.; Jeon, J.W. Juvenile Taekwondo player's coping and deviant behavior base on the level of stress. Korean J. Sports Sci. 2011, 20, 377-391.

31. Cho, E.-H.; Jang, C.-Y.; Kwak, Y.-S.; Kim, E.-J. The Psychometric Characteristic of the Taekwondo Electronic Protector Cognition Scale: The Application of the Rasch Model. Int. J. Environ. Res. Public Health 2020, 17, 3684. [CrossRef] [PubMed]

32. Jeon, M. Analysis of point deduction patterns in Taekwondo using association rule learning. Int. J. Perform. Anal. Sport 2019, 19, 323-330. [CrossRef]

33. Menescardi, C.; Falco, C.; Ros, C.; Morales-Sánchez, V.; Hernández-Mendo, A. Technical-tactical actions used to score in taekwondo: An analysis of two medalists in two Olympic Championships. Front. Psychol. 2019, 10, 2708. [CrossRef]

34. United Nations Development Programme. What Are the Sustainable Development Goals? 2021. Available online: https: / / www.undp.org/sustainable-development-goals (accessed on 13 October 2021). 
35. International Olympic Committee. Remarks on the Occasion of the Adoption of the UN Sustainable Development Goals: UN Sustainable Development Summit; International Olympic Committee: Lausanne, Switzerland, 2015.

36. Shilbury, D.; Sotiriadou, K.P.; Green, B.C. Sport development. Systems, policies and pathways: An introduction to the special issue. Sport Manag. Rev. 2008, 11, 217-223. [CrossRef]

37. Ha, J.P.; Lee, K.; Ok, G. From development of sport to development through sport: A paradigm shift for sport development in South Korea. Int. J. Hist. Sport 2015, 32, 1262-1278. [CrossRef]

38. Ha, J.P.; Ha, J. From MDGs to SDGs: The Conceptual Definition of Sport for Development (SFD) Movement and Advanced Strategies for SFD Program. Korean J. Phys. Educ. 2016, 55, 393-402.

39. Moenig, U.; Kim, Y.I. The Early Globalization Process of Taekwondo, from the 1950s to 1971. Int. J. Hist. Sport 2021, 37, 1-20. [CrossRef]

40. MedlinePlus. Stress and Your Health. 2021. Available online: https://medlineplus.gov/ency/article/003211.htm (accessed on 28 March 2021).

41. World Health Organization. Mental Health: Strengthening Our Response. 2018. Available online: https://www.who.int/newsroom/fact-sheets/detail/mental-health-strengthening-our-response (accessed on 28 March 2021).

42. National Institute of Mental Health. Mental Illness. 2021. Available online: https://www.nimh.nih.gov/health/statistics/mentalillness.shtml (accessed on 28 March 2021).

43. Korean Ministry of Health and Welfare. 2016 Mental Illness Survey. 2017. Available online: http://www.mohw.go.kr/react/jb/ sjb030301vw.jsp?PAR_MENU_ID=03\&MENU_ID=032901\&CONT_SEQ=339138\&page=1 (accessed on 12 October 2021).

44. Korea National Assembly Research Service. Mental Health Status of Children and Adolescents, Support System and Improvement Direction. 2021. Available online: https:/ / www.nars.go.kr/report/view.do?cmsCode=CM0155\&brdSeq=34664 (accessed on 12 October 2021).

45. Hirvensalo, M.; Lintunen, T. Life-course perspective for physical activity and sports participation. Eur. Rev. Aging Phys. Act. 2011, 8, 13-22. [CrossRef]

46. Kim, D.H.; Bassett, S.M.; So, S.; Voisin, D.R. Family stress and youth mental health problems: Self-efficacy and future orientation mediation. Am. J. Orthopsychiatry 2019, 89, 125-133. [CrossRef]

47. Mazza, J.J.; Reynolds, W.M. A longitudinal investigation of depression, hopelessness, social support, and major and minor life events and their relation to suicidal ideation in adolescents. Sucide Life Threat. Behav. 1998, 28, 358-374.

48. Mahmoud, J.S.R.; Staten, R.T.; Hall, L.A.; Lennie, T.A. The relationship among young adult college students' depression, anxiety, stress, demographics, life satisfaction and coping styles. Issues Ment. Health Nurs. 2012, 33, 149-156. [CrossRef]

49. Beiter, R.; Nash, R.; McCrady, D.; Rhoades, M.; Linscomb, M.; Clarahan, M.; Sammut, S. The prevalence and correlates of depression, anxiety and stress in a sample of college students. J. Affect. Disord. 2015, 173, 90-96. [CrossRef]

50. Novotney, A. Students under pressure. Monit. Psychol. 2014, 45, 37-41.

51. Petrovic, K. The Benefits of Taekwondo Training for Undergraduate Students: A Phenomenological Study. Societies 2017, 7, 27. [CrossRef]

52. Gil, D.; Song, I.Y. Modeling and management of big data: Challenges and opportunities. Future Gener. Comput. Syst. 2016, 63, 96-99. [CrossRef]

53. Beyer, M.A.; Laney, D. The Importance of "Big Data": A Definition; Gartner: Stamford, CT, USA, 2012.

54. Carter, P. Big Data Analytics: Future Architectures, Skills and Roadmaps for the CIO. IDC 2011, September. Available online: https:/ / docplayer.net/2544559-Big-data-analytics-future-architectures-skills-and-roadmaps-for-the-cio.html (accessed on 30 January 2021).

55. Manyika, J.; Chui, M.; Brown, B.; Bughin, J.; Dobbs, R.; Roxburgh, C.; Byers, A.H. Big Data: The Next Frontier for Innovation, Competition, and Productivity; McKinsey Global Institute: Seattle, WA, USA, 2011.

56. Xing, E.P.; Ho, Q.; Dai, W.; Kim, J.K.; Wei, J.; Lee, S.; Zheng, X.; Xie, P.; Kumar, A.; Yu, Y. Petuum: A new platform for distributed machine learning on big data. IEEE Trans. Big Data 2015, 1, 49-67. [CrossRef]

57. Shin, D.H. Demystifying big data: Anatomy of big data developmental process. Telecommun. Policy 2016, 40, 837-854. [CrossRef]

58. Shin, D. A socio-technical framework for internet-of-things design. Telemat. Inform. 2014, 31, 519-531. [CrossRef]

59. Park, S.-U.; Ahn, H.; Kim, D.-K.; So, W.-Y. Big Data Analysis of Sports and Physical Activities among Korean Adolescents. Int. J. Environ. Res. Public Health 2020, 17, 5577. [CrossRef]

60. Feldman, R.; Sanger, J. The Text Mining Handbook: Advanced Approaches in Analyzing Unstructured Data; Cambridge University Press: Cambridge, UK, 2007.

61. Mining Text Data; Aggarwal, C.C.; Zhai, C. (Eds.) Springer Science \& Business Media: New York, NY, USA, 2012. [CrossRef]

62. Aggarwal, C.C. Machine Learning for Text; Springer: Cham, Switzerland, 2018.

63. Sinoara, R.A.; Camacho-Collados, J.; Rossi, R.G.; Navigli, R.; Rezende, S.O. Knowledge-enhanced document embeddings for text classification. Knowl. Based Syst. 2019, 163, 955-971. [CrossRef]

64. Voss, K.E.; Spangenberg, E.R.; Grohmann, B. Measuring the hedonic and utilitarian dimensions of consumer attitude. J. Mark. Res. 2003, 40, 310-320. [CrossRef]

65. Zhang, Y.; Gong, L.; Wang, Y. An improved TF-IDF approach for text classification. J. ZheJiang Univ. Sci. 2005, 6, 49-55. [CrossRef]

66. Otte, E.; Rousseau, R. Social network analysis: A powerful strategy, also for the information sciences. J. Inf. Sci. 2002, 28, 441-453. [CrossRef] 
67. Scott, N.; Baggio, R.; Cooper, C. Network Analysis and Tourism from Theory to Practice; Cromwell Press: Trowbridge, UK, 2008.

68. Ban, H.-J.; Choi, H.; Choi, E.-K.; Lee, S.; Kim, H.-S. Investigating Key Attributes in Experience and Satisfaction of Hotel Customer Using Online Review Data. Sustainability 2019, 11, 6570. [CrossRef]

69. Jun, C.N.; Chung, C.J. Big data analysis of local government 3.0: Focusing on Gyeongsangbuk-do in Korea. Technol. Forecast. Soc. Change 2016, 110, 3-12. [CrossRef]

70. Oh, C.W. Analysis of Meaning of Social Conflict Discussion in Korea: Focusing on Key Word Network in Major Portals. J. Polit. Commun. 2017, 45, 37-67.

71. Ann, M.S. Multicultural keywords and network analysis using big data. Soc. Converg. Knowl. Trans. 2018, 6, 87-104.

72. Sung, Y.A.; Kim, K.W.; Kwon, H.J. Big Data analysis of Korean travelers' behavior in the Post-COVID-19 Era. Sustainability 2021, 13, 310. [CrossRef]

73. Jang, H.; Park, M. Social media, media and urban transformation in the context of overtourism. Int. J. Tour. Cities 2020, 6, 233-260. [CrossRef]

74. Park, T.H.; Kim, W.I.; Park, S.; Ahn, J.; Cho, M.K.; Kim, S. Public interest in acne on the internet: Comparison of search information from Google trends and Naver. J. Med. Internet Res. 2020, 22, e19427. [CrossRef]

75. Pettersson, S.; Berg, C.M. Hydration status in elite wrestlers, judokas, boxers, and taekwondo athletes on competition day. Int. J. Sport Nutr. Exerc. Metab. 2014, 24, 267-275. [CrossRef]

76. da Silva Santos, J.F.; Takito, M.Y.; Artioli, G.G.; Franchini, E. Weight loss practices in Taekwondo athletes of different competitive levels. J. Exerc. Rehabil. 2016, 12, 202-208. [CrossRef]

77. Costa, D.D.O.; Oliveira, L.D.S.; Sena, E.A.D.; Lima, F.F.D.; Silva, A.S. Pre-competition physical, physiological and psychosocial states of taekwondo athletes. J. Phys. Educ. 2018, 29, e2913.

78. Franchini, E.; Brito, C.J.; Artioli, G.G. Weight loss in combat sports: Physiological, psychological and performance effects. J. Int Soc. Sports Nutr. 2012, 9, 52. [CrossRef]

79. Yaegaki, M.; Umeda, T.; Takahashi, I.; Yamamoto, Y.; Kojima, A.; Tanabe, M.; Yamai, K.; Matsuzaka, M.; Sugawara, N.; Nakaji, S. Measuring neutrophil functions might be a good predictive marker of overtraining in athletes. Luminescence 2008, 23, 281-286. [CrossRef]

80. Blecharz, J. Athlete in a Situation of Physical Injury; AWF w Krakowie: Kraków, Poland, 2008.

81. Litwic-Kaminska, K. Resiliency and stress experience among judo and taekwondo athletes. J. Combat Sports Martial Arts 2013, 4 , 167-172. [CrossRef]

82. Korea Ministry of Culture, Sports and Tourism. Public-Private Joint "Sports Innovation Committee" Launched for Structural Innovation in the Sports Field. 2019. Available online: https://www.mcst.go.kr/kor/s_notice/press/pressView.jsp?pSeq=17098 (accessed on 23 January 2021).

83. Lindner, J.B.K.J. Withdrawal from competitive youth sport: A retrospective ten-year study. J. Sport Behav. 2002, 25, 7-8.

84. Isoard-Gautheur, S.; Guillet-Descas, E.; Gustafsson, H. Athlete burnout and the risk of dropout among young elite handball players. Sport Psychol. 2016, 30, 123-130. [CrossRef]

85. Röger, U.; Rütten, A.; Heiko, Z.; Hill, R. Quality of talent development systems: Results from an international study. Eur. J. Sport Soc. 2010, 7, 7-19. [CrossRef]

86. Barley, O.R.; Chapman, D.W.; Abbiss, C.R. Weight loss strategies in combat sports and concerning habits in mixed martial arts. Int. J. Sports Physiol. Perform. 2018, 28, 1-24. [CrossRef] [PubMed]

87. Artioli, G.G.; Gualano, B.; Franchini, E.; Scagliusi, F.B.; Takesian, M.; Fuchs, M.; Lancha, A.H., Jr. Prevalence, magnitude, and methods of rapid weight loss among judo competitors. Med. Sci. Sports Exerc. 2010, 42, 436-442. [CrossRef]

88. Ribisl, P.M.; Herbert, W.G. Effects of rapid weight reduction and subsequent rehydration upon the physical working capacity of wrestlers. Res. Q. Am. Ass. Health 1970, 41, 536-541. [CrossRef]

89. Landers, D.M.; Arent, S.M.; Lutz, R.S. Affect and cognitive performance in high school wrestlers undergoing rapid weight loss. J. Sport Exerc. Psychol. 2001, 23, 307-316. [CrossRef] [PubMed]

90. Maughan, R.J.; Shirreffs, S.M. Recovery from prolonged exercise: Restoration of water and electrolyte balance. J. Sports Sci. 1997, 15, 297-303. [CrossRef]

91. Burke, L.M.; Cox, G.R. Nutrition in combat sports. In Combat Sports Medicine; Springer: London, UK, 2009 ; pp. 1-20.

92. Caldwell, J.E.; Ahonen, E.; Nousiainen, U. Differential effects of sauna-, diuretic-, and exercise-induced hypohydration. J. Appl. Physiol. 1984, 57, 1018-1023. [CrossRef]

93. Horstman, D.H.; Horvath, S.M. Cardiovascular adjustments to progressive dehydration. J. Appl. Physiol. 1973, 35, 501-504. [CrossRef] [PubMed]

94. Nielson, B.; Kubica, R.; Bonnesen, A.; Rasmussen, I.; Stoklosa, J.; Wilk, B. Physical work capacity after dehydration and hyperthermia: A comparison of the effects of exercise versus passive heating and sauna and diuretic dehydration. Scand. J. Sports Sci. 1981, 3, 2-10.

95. Veech, R.L. The therapeutic implications of ketone bodies: The effects of ketone bodies in pathological conditions: Ketosis, ketogenic diet, redox states, insulin resistance, and mitochondrial metabolism. Prostaglandins Leukotr. Essent. Fat. Acids 2004, 70, 309-319. [CrossRef]

96. Perlman, B.; Hartman, E.A. Burnout: Summary and future research. Hum. Relat. 1982, 35, 283-305. [CrossRef]

97. Smith, R.E. Toward a cognitive-affective model of athletic burnout. J. Sport Exerc. Psychol. 1986, 8, 36-50. [CrossRef] 
98. Gustafsson, H.; Skoog, T. The mediational role of perceived stress in the relation between optimism and burnout in competitive athletes. Anxiety Stress Coping 2012, 25, 183-199. [CrossRef]

99. Moving the youth development message: Turning a vague idea into a moral imperative. In Trends in Youth Development: Visions, Realities, and Challenges; Benson, P.L.; Pittman, K.J. (Eds.) Kluwer Academic Publishers: Boston, MA, USA, 2001.

100. Zarrett, N.; Fay, K.; Li, Y.; Carrano, J.; Phelps, E.; Lerner, R.M. More than child's play: Variable-and pattern-centered approaches for examining effects of sports participation on youth development. Dev. Psychol. 2009, 45, 368. [CrossRef]

101. Korea Ministry of Culture, Sports and Tourism. Research on Establishing "Basic Plan for Taekwondo Promotion (2014 2018)". 2013. Available online: http:/ /www.prism.go.kr/homepage/theme/retrieveThemeDetail.do?leftMenuLevel=110\&cond_brm_ super_id=NB000120061201100039075\&research_id=1371000-201400069 (accessed on 24 January 2021).

102. Korea Institute of Sport Science. Problems of the College Admissions System for Sports Experts and Research on Improvement Plans. 2011. Available online: https://www.sports.re.kr/pyxis-api/1/digital-files/3c129d2b-f8d5-4892-a9ca-6b34de302443 (accessed on 25 January 2021).

103. National Collegiate Athletic Association. Mental Health Best Practices. 2021. Available online: https://www.ncaa.org/sportscience-institute/mental-health-best-practices (accessed on 30 April 2021). 